\title{
Mediating household energy transitions through co-design in urban Kenya, Uganda and South Africa
}

\author{
Amollo Ambole ${ }^{\mathrm{a}, *}$, Josephine Kaviti Musango ${ }^{\mathrm{b}}$, Kareem Buyana ${ }^{\mathrm{c}}$, Madara Ogot ${ }^{\mathrm{d}}$, Christer Anditi $^{\mathrm{a}}$, \\ Baraka Mwau ${ }^{\mathrm{e}}$, Zora Kovacic ${ }^{\mathrm{b}}$, Suzanne Smit ${ }^{\mathrm{b}}$, Shuaib Lwasa ${ }^{\mathrm{c}}$, Gloria Nsangi ${ }^{\mathrm{c}}$, Hakimu Sseviiri ${ }^{\mathrm{c}}$, \\ Alan C Brent ${ }^{\mathrm{f}, \mathrm{g}}$ \\ ${ }^{\text {a }}$ School of the Arts and Design, University of Nairobi, Kenya \\ ${ }^{\mathrm{b}}$ School of Public Leadership, Urban Modelling and Metabolism Assessment (uMAMA), Stellenbosch University, South Africa \\ ${ }^{\mathrm{c}}$ Urban Action Lab, Makerere University, Uganda \\ ${ }^{\mathrm{d}}$ Department of Mechanical \& Manufacturing Engineering, University of Nairobi, Kenya \\ e Planning Consultant, Kenya \\ ${ }_{\mathrm{f}}^{\mathrm{f}}$ Department of Industrial Engineering, Centre for Renewable and Sustainable Energy Studies (CRSES), uMAMA, Stellenbosch University, South Africa \\ ${ }^{\mathrm{g}}$ Sustainable Energy Systems, Engineering and Computer Science, Victoria University of Wellington, New Zealand
}

\section{A R T I C L E I N F O}

\section{Keywords:}

Africa

Energy transitions

Transdisciplinary co-design

Urban informal settlements

\begin{abstract}
A B S T R A C T
Approaches to providing sustainable energy in cities have generated considerable interest in academic and policy circles. The development of this body of work, however, has not shed much light on the modes of intermediation that are needed to reconfigure urban energy systems towards sustainability in energy-poor countries. This paper focuses on the role of academics as knowledge intermediaries who can trigger cross-sector collaborations around innovations for a sustainable energy transition in African cities. The research presented here was generated by an interdisciplinary research team made up of partners in Kenya, Uganda and South Africa. The research partners set out to better understand how sustainable energy transitions can be achieved through collaborative efforts between community members, experts and policy actors in the three countries. This paper provides evidence-based reflections on how the research partners used participatory methods to facilitate solution co-design and knowledge co-production over a period of two years under the Leading Integrated Research for Agenda 2030 in Africa (LIRA 2030) program. A key knowledge outcome of the research partnership is an improved understanding of how transdisciplinary research across the sub-region can be used to unearth the socio-spatial, cultural and political dimensions of energy in relation to other urban services such as health and housing. Based on this understanding, the paper proposes transdisciplinary co-design as a promising approach to providing sustainable energy in urban informal settlements in Sub-Saharan Africa.
\end{abstract}

\section{Introduction}

Universal access to sustainable energy is a key global concern that is driven by the urgency to provide for burgeoning populations in the South [1] and mitigate the effects of greenhouse gas emissions in the North [2] in order to guarantee a sustainable energy future for all. This concern is engendered in the Sustainable Energy for All (SEforALL) initiative that seeks to work with:

“...leaders in government, the private sector and civil society to drive further, faster action toward achievement of Sustainable Development Goal 7, which calls for universal access to sustainable energy by 2030 , and the Paris Climate Agreement, which calls for reducing greenhouse gas emissions to limit climate warming to below 2 degrees Celsius." [3].

Launched at the UN General assembly in 2011, SEforALL has three main objectives of: "ensuring universal access to modern energy services, doubling the global rate of improvement in energy efficiency, and doubling the share of renewable energy in the global energy mix." (ibid).

This paper focuses on the role of academics in this push for sustainable energy for all. As knowledge intermediaries, academics are well placed to facilitate cross-sector collaborations around innovations for sustainable energy transition, more so in the case of African cities that are some of the fasted growing in the world [4]. We reflect on our own work as knowledge intermediaries and integrators by situating our

\footnotetext{
* Corresponding author.

E-mail address: Lambole@uonbi.ac.ke (A. Ambole).
} 
studies in African cities at the cross-section of discourses on energy transitions, energy communities and transdisciplinary research. Our main argument is that transition towards sustainable energy in subSaharan Africa calls on local researchers to become intermediaries who can engage in transdisciplinary studies that enhance cross-sector collaborations between communities, practitioners and policy actors. If these cross-sector collaborations are sustained, then they in turn can support the co-design of trans-local energy communities that meet the growing demand for clean household energy supply, access, and management in Africa's growing cities. Ultimately, we present our work as social experiments that can support technological revolutions in the energy sector in urban Africa.

The rest of the paper has three main sections. Section 2 interrogates the sustainable energy discourse by highlighting the mixed results of energy efforts in Africa, which are strongly influenced by global forces, but are yet to provide adequately for a majority of African citizens; Global forces that have led to energy liberalization globally, have in some cases reproduced inequalities in Africa, while driving niche innovations in Western industrialized countries. Examples of niche innovations that are thriving in the West are energy communities that have switched to renewable energy. We argue that cross-sector collaborations and transdisciplinary approaches foreground such energy communities. In Section 3, we use three of our case studies to showcase how transdisciplinary research enabled an overarching understanding of the energy challenge and laid the groundwork for co-designing energy communities in three African cities. Section 4 delves further into the interactions that are required to transform policy and funding landscapes. Here, the nexus approach is introduced as a lens for better understanding and managing these interactions. We conclude by proposing that local researchers embedded in African cities should work towards the co-creation of agile, trans-local networks that can harness transnational capital to radically improve household energy access for informal settlement communities.

\section{Sustainable energy for all?}

Worldwide, the energy market has undergone liberalization since the 1980s with mixed results for different countries [5]. In developing countries, multiple projects and programs have been launched, requiring governments to institute mechanisms and policies that will enable growth in the energy sector [6]. In this regard, development partners such as the World Bank have supported liberalization of the energy sectors in African countries resulting in variegated energy infrastructures (ibid). More recently, China has become a global contender in the energy sector, with $33 \%$ of its investments in Africa going towards energy. ${ }^{1}$ At the same time, Western countries have pursued liberalization and other strategies that have spawned shifts in technology and knowledge production, resulting in a range of transition work [7]. Consequently, current conceptualizations of energy transitions are dominated by examples from Western industrial contexts [8].

In sub Saharan Africa, the poverty alleviation narrative has dominated energy research, resulting in a diminished understanding of transition pathways of countries in the sub-continent $[9,10]$. In this regard, the large-scale national projects that attract transnational capital are yet to translate into substantial livelihoods improvements and knowledge advancements. In Kenya for example, the energy sector has remained fairly centralized and controlled by the government, while attracting transnational capital investment for large-scale, grid-based renewable energy projects like the Olkaria geothermal plant that was a first in Africa, and the Turkana wind farm that is the largest in Africa. ${ }^{2}$ Similarly, the Ugandan government has facilitated the liberalization of the country's energy sector, with significant transnational capital

\footnotetext{
${ }^{1}$ http://www.aei.org/china-global-investment-tracker/.

${ }^{2}$ http://kengen.co.ke.
}

directed at building more hydropower plants and exploiting geothermal energy. $^{3}$

South Africa's energy history is different having developed in an Apartheid State that exploited the generous coal deposits in the country to provide the cheapest electricity prices in the world for a long time [11]. However, in 2008, South Africa went through a supply crisis that pointed to its unsustainable dependency on coal. Being the largest greenhouse emitter in Africa, South Africa is pursuing initiatives such as the Renewable Energy Independent Power Producer Program (REIPPP) to meet demand and mitigate environmental degradation [12].

Admittedly, a number of small-scale energy entrepreneurs have made inroads into the supply of off-grid solar for bottom-of-the-pyramid customers in many African countries. However, innovations in this space are highly fragmented and disconnected from research [13]. Additionally, many studies have focused on rural energy-poverty since most of Africa is still rural [14-16]. Nonetheless, growth projections indicate that African cities will experience the highest growth rates, necessitating a keen look into the resulting urban energy poverty and its outcomes. Informality is currently a key feature of sub Saharan African cities, in which many urban dwellers have little or no access to basic services such as adequate housing or clean household energy among other services [4].

Poor access to clean, modern energy means that most households in sub Saharan Africa rely on biomass fuels such as wood, charcoal or dung, which are combusted in poorly ventilated dwellings, using inefficient stoves, thereby producing indoor air pollutants such as: carbon monoxide and small particles matter, nitrogen oxides, benzene, butadiene, formaldehyde and polyaromatic hydrocarbons [10,17]. Frequent inhalation of these pollutants may cause respiratory infections; eye infections; or exacerbate other conditions such as asthma and tuberculosis. Indoor air pollution is also associated with low birth weight of babies and higher incidences of eclampsia symptoms in women. Consequently, indoor emissions from burning of biomass fuels is one of the highest risk factors of death in low-income countries [18]. According to the World Health Organization, of the 4.3 million deaths globally attributable to household air pollution in 2012, almost 600,000 occured in Africa, while 19, 000 deaths occur in high income countries. $^{4}$

The common alternative to biomass fuels in low-income settings is paraffin (kerosene) which produces less indoor air pollutants but is often the cause of fires and poisonings [19]. In addition, many households in urban informal settlements have Illegal electricity connections. These may cause widespread settlement fires leading to huge losses in property or even life [20]. In some cases, cartels that control these services charge exorbitant fees [21]. Worse still, the considerable amount of time spent in sourcing for fuel in poorly planned settlements is time that is taken away from other income generating activities, family responsibilities and opportunities for self-improvement [22].

To tackle the challenge of energy-poverty in developing countries, existing interventions have focused on two main goals of: (i) providing more sustainable and clean energy sources and fuels; and (ii) improving health outcomes for poor households [23]. These goals have been implemented using one or a combination of three options: changing the fuel type by for example supplying improved biomass fuel types, such as low smoke briquettes [24]; improving the ventilation of the living environment such as through better kitchen design [25]; or adjusting user behaviour, for example by changing cooking practices to reduce smoke inhalation [23].

These three implementation options have nevertheless failed to significantly reduce the energy poverty challenge at the household level because they are often implemented in isolation, or with little

\footnotetext{
${ }^{3}$ https://www.era.or.ug/index.php/oppotunities/renewal-energyinvestment-guide.

${ }^{4}$ https://www.who.int/phe/health_topics/outdoorair/databases/en/.
} 
understanding of the socio-cultural, behavioural and economic specificities of targeted populations [26,27]. For example, studies show that improved biomass cook stoves do not achieve significant improvements in health outcomes as anticipated because their performance in the field is poor compared to laboratory tests [28]. Household energy interventions also fail to adequately address the gendered dimension of energy-poverty thus reproducing gender inequalities in poor settlements $[29,30]$. Notable studies in Africa further show that poor residents, in varying degrees, are aware that biomass fuels are a source of air pollution and subsequent health risks. However, due to income constraints, they are often resigned to their situation as they prioritize other household needs $[27,31,32]$. We therefore argue that a co-design process is indispensable in understanding and tackling the energy poverty challenge and its health outcomes.

\subsection{Co-designing energy solutions}

Worldwide, there is a growing consensus for a broader understanding of energy and its related health outcomes as a complex, multidimensional challenge requiring multi-perspective interventions [33-35]. As such, Energy transition studies focus on the socio-technological, spatial and even political interactions between micro, meso, and macro levels of energy governance and access. Borrowing from the multi-level perspective approach, such studies look at how energy regimes at the meso levels are challenged by niche innovations at the micro-level and by policy and capital landscapes at the macro-level $[12,36]$.

Within energy transition work, a growing body of literature on energy communities has paid closer attention to the multi-dimensionality of household energy. However, most of these studies are shaped almost entirely by industrialized contexts and might not therefore be well suited for unmet energy markets [37]. In a review of 70 community energy studies, Klein and Coffey [38] found that most were done in industrialized countries in Europe, the United Kingdom (UK), United States and Australia. Only one study was from a developing country context.

According to the Community Energy Strategy of the Department of Energy and Climate Change, UK, 'community energy' is defined as:

'...community projects or initiatives focused on the four strands of reducing energy use, managing energy better, generating energy or purchasing energy. This included communities of place and communities of interest. These projects or initiatives shared an emphasis on community ownership, leadership or control where the community benefits.' ([39], p. 20).

Since 2008, 5000 community energy groups across the UK have actively promoted energy projects that are motivated by shared social benefits and have wider interest on sustainability. In Germany, community energy made up $40 \%$ of the country's total renewable energy capacity by 2010 (ibid. p. 21). Notably, these community energy projects focus on the transition from large-scale, centralized, fossil-based systems to smaller decentralized renewable energy systems that can be managed locally [40,41]. The configuration of these communities is nevertheless varied in terms of technology and scale, using a wide range of ownership structures [42,43]. Despite their variety, the commonality across these studies is the thematic confluence of arguments drawn from works in energy transition, community participation and crosssector collaboration [44].

In cases where researchers play an active role in facilitating engagement in community energy, transdisciplinarity has been used to explain the concurrent interactions that occur between disciplines such as 'energy engineering' and 'social-environmental geography', and beyond the disciplines such as between experts, community members and policy actors [45]. In this regard, researchers play an active role in unearthing 'current energy knowledges' using problem-solving approaches that are iterative and reflexive (ibid). These aspects of transdisciplinarity tally with the co-design stance of the product-service-system approach for distributed renewable energy [46,47].

Proponents of co-designing solutions with communities insist that community members as end users of solutions, must be included in the design process since they are experts of their own reality. [48]. This is especially true for communities that have previously been marginalised by formal, top-down design approaches that fail to integrate community value systems and realities [49]. By integrating community needs and values, researchers have demonstrated that solutions have a better chance of being adopted and used sustainably [50,51]. This way of designing has further been promoted by product designers in methods such as design thinking [52] and social innovation [53]. In this paper, we highlight how these design-oriented methods can be usefully integrated with other research methods given the complexity of energy transition processes. We also demonstrate how co-design is 'slow' and involving and therefore difficult to initiate and sustain [51].

The growing evidence that energy transition requires co-designing with a wide range of actors using multiple perspectives, calls for a better understand of how such participation can be facilitated and sustained in Africa's burgeoning cities that are expanding and densifying much faster than services can be provided [4]. The few existing transition studies in developing countries have focused on isolated project-based experiments that are yet to develop collectively into a body of niche innovation management [40]. There is therefore ample opportunity and urgency to offer correlational evidence-based studies that will shape the transition pathway for developing countries.

To fill this gap, we provide evidence-based reflections on how we experimented on different types of engagements at multiple levels in three African cities, with the aim of understanding and tackling the energy challenge in urban informal settlements. This focus on informal settlements further highlights the interrelated nature of energy with health and housing, among other basic needs that a majority of Africa's urbanites struggle to obtain on a daily basis.

Our reflections from the 'Co-designing Energy Communities' (CoDEC) research project are based on a two-year collaborative study between researchers from University of Nairobi in Kenya; Makerere University in Uganda; and Stellenbosch University in South Africa. The project, which began in 2017, was aimed at integrating solutions to the energy-health nexus challenge in three urban informal settlements: Mathare, Kasubi-Kawaala, and Enkanini in Kenya, Uganda and South Africa respectively.

\section{Energy research case studies in Nairobi, Kampala and Stellenbosch}

In this section, the brief description of case study sites in informal settlements sets the stage for discussing the transdisciplinary approach of the CoDEC research project in Nairobi city, Kenya; Kampala city, Uganda; and Stellenbosch town, South Africa. The case studies were selected through convenience sampling, meaning that the research teams in each country had prior research experience themselves with the case studies, or were building on existing research by their host universities in their respective cases and contexts. Through convenience sampling, the researchers were thus able to work with participants who were easily accessible and were willing to participate, as well as carry out field work in areas of geographical proximity [54]. In this way, the teams leveraged existing knowledge and partnerships to increase the impact of their engagements.

Nevertheless, there was a dearth of household data on energy and related issues, necessitating baseline studies in the three informal settlement case studies. The baseline study findings thus became as a point of departure for the project's aim to establish long-term, cross-sector collaborations that would enhance livelihoods in the settlements.

In Nairobi, the baseline survey study was conducted in Mathare Valley, an urban informal settlement that consists of 80,309 residents as of the last census in 2009 Kenya National Bureau of Statistics, 2010. 
The 2009 Kenya Population and Housing Census. Government of Kenya.(KNBS, 2010). The baseline study revealed that $93 \%$ of residents are connected to the national grid, although $50 \%$ of those connections are indirect, meaning that they are not provided directly by the utility provider and are therefore not metered. Self-made 'electricians' in the settlement connect households to the grid at a minimal monthly charge that covers repair and maintenance. Paraffin is also the most widely used source of cooking fuel in the settlement, although small electric cookers are seen as a cheap option by some households that are not metered.

The Kampala baseline study was carried out in Kasubi-Kawaala area, which consists of two informal settlements in the Rubaga division of Kampala city, Uganda. Although the settlements are recognized by government, population data is scanty. Estimates by the Ministry of Lands, Housing and Urban Development are that Kasubi and Kawaala have a total of 92,000 residents. ${ }^{5}$ The CODEC baseline study showed that $85 \%$ of residents of Kasubi-Kawaala have electricity connections, with $10 \%$ of these connections being indirect. In this regard, indirect connections were of two types: unmetered self-connections to the grid, as well as connections to other households that are connected to the grid. In the first instance, householders paid a fee to a local electrician while in the second instance, a fee was collected by the metered household. For cooking, charcoal was the most widely used fuel although a local community project provided briquettes from food waste.

The third case study in Stellenbosch, South Africa, focused on Enkanini informal settlement. According to an enumeration study of the settlement in 2012, the settlement was home to an estimated 4082 residents who began settling in the area in 2006 [55]. However, the population nearly doubled to 8000 people as at 2015 [56]. Enkanini is not formerly connected to the national grid but $10 \%$ of householders are indirectly connected to metered households in nearby Kayamandi area (Authors, upcoming). As at November 2016, 767 households had been connected to solar home systems provided by the iShack project and other solar service providers. ${ }^{6}$ The iShack package includes light bulbs, a television set, cell-phone-charging, tablet, music system, and a fridge. In addition, the iShack project received policy support by the Municipality of Stellenbosch which provides a free basic electricity subsidy on behalf of each household that participates in the scheme. ${ }^{7}$

An in-depth comparative analysis of the baseline studies results revealed substantial differences in the three cases (Authors, upcoming). Aspirations for improving livelihoods were however common in all three cases as community members continued to engage with the researchers for the duration of the study.

\subsection{Transdisciplinary approach to co-design}

A prevailing understanding of transdisciplinary research is that it entails collaboration between different communities of place and of practice [57]. In the CoDEC project, a transdisciplinary approach was anchored by the place-based realities of the three informal settlements, thus providing a context-specific perspective to the engagements. In essence therefore, engaging with communities of place foregrounded the aspiration of building a community of practice that would influence positive policy changes for the energy challenge in the sub-region.

CoDEC project partners were keen to build on existing expertise in each of the case studies, and therefore came together as local research teams that had prior research experience in their local contexts. In this regard, the individual research teams from University of Nairobi,

\footnotetext{
${ }^{5}$ http://askyourgov.ug/request/37/response/38/attach/2/Rubaga $\% 20$ Municipality.pdf.

${ }^{6}$ This was obtained from a GIS mapping activity by Stellenbosch research team. The map cannot be shared due to confidentiality clause for the households with indirect connections.

${ }^{7}$ https://www.ishackproject.co.za/.
}

Makerere University, and Stellenbosch University had each done urban related research in the respective informal settlement case studies. This prior experience allowed the partners to focus further on how a collaborative and transdisciplinary research approach would be implemented in the project. In line with transdisciplinary research epistemology, the project aimed to co-design solutions and co-produce socially relevant knowledge that would inform sustainable energy transitions [58]. More specifically, the partners set out to: use evolving and reflexive methodologies; transcend boundaries of disciplines; seek the participation of stakeholders; and aim for social transformation [59].

Table 1 provides a summary of research engagement activities undertaken by local research teams in each country, as well as group reflections exercises as regional partners. For the most part, the partners were able to keep to the general work plan on activities. However, emerging circumstances called for flexibility in how the activities were conducted. For example, identified stakeholders from the stakeholder mapping exercise were not necessarily the same ones who participated in the project. In this regard, stakeholder participation depended more on leveraging pre-existing relationships through informal interactions rather than through structured formality. Additionally, the initial objective of the research was to tackle household energy and its interrelated health outcomes. However, housing and gender issues also emerged as important nexus concerns that could not be ignored.

To engage communities of place as a precursor to building a community of practice, the partners co-opted residents from the case studies as community co-researchers. In this way, the baseline studies which included household surveys and participatory mapping were not just an opportunity to collect and analyze data, but to also acknowledge that community members as knowledge producers and experts of their lived experience. Admittedly, the research partners remain the custodians of the produced knowledge, and by virtue of their profession, hold the highest interest in the knowledge products of the project.

In the Kenya case, the researchers experimented further with a variety of community engagement methods borrowed from design thinking. In a design thinking workshop, participants drawn from Mathare, from the field of health and from the Ministry of Energy, engaged in rapid-prototyping exercises to co-design product-servicesystems (PSS). PSS is a model that has been popularized by industrial designers who argue that sustainable production requires a full lifecycle approach that considers how products are made, used and maintained. As such, the design process encompasses industrial partnerships, stakeholder interactions, and policy actions that drive towards environmental and socio-ethical benefits [46]. In terms of sustainable energy, PSS models have been considered as distributed, renewable energy (DRE) systems, which contrast with the centralized systems commonly controlled by national utility providers [47].

The result of the design thinking workshop was a proposed PSS model that not only focused on renewable energy, but also considered cost, health benefits, awareness, alongside technology and infrastructure. These considerations emerged as the key concerns for participants in the inspiration phase. In consultation with energy experts from Stockholm Environment Institute (Nairobi office) the CoDEC researchers refined the model into an overarching framework for an energy knowledge network that would coordinate and sustain multi-stakeholder efforts. The recommendation is that such a network can be operationalized as a centre or a 'real-world laboratory' that supports interfaces between science, policy and community [60].

\subsection{Science advocacy: influencing policy}

Energy policy and regulation in Kenya, Uganda and South Africa all point to energy as a key factor in development.

In line with the National Development Plan of South Africa, the Department of Energy state that: 
Table 1

Summary of research activities and engagement by CoDEC project partners.

Source: Authors.

Project research objective: to integrate solutions to the energy-health challenge in urban informal settlements in Africa

\begin{tabular}{|c|c|c|c|}
\hline Research teams from: & University of Nairobi - CoDEC host university & Makerere University & Stellenbosch University \\
\hline $\begin{array}{l}\text { Previous research } \\
\text { focus }\end{array}$ & Social innovation for urban change & Sustainable urban development & Urban metabolism and renewable energy \\
\hline Disciplinary strength & $\begin{array}{l}\text { Product design; Design thinking; Strategic project } \\
\text { management }\end{array}$ & Urban sociology; Gender mainstreaming & $\begin{array}{l}\text { System dynamics modelling; Renewable energy } \\
\text { policy }\end{array}$ \\
\hline $\begin{array}{l}\text { Urban informal } \\
\text { settlement case }\end{array}$ & Mathare in Nairobi, Kenya & Kasubi-Kawaala in Kampala, Uganda & Enkanini in Stellenbosch, South Africa \\
\hline
\end{tabular}
study

Study methods

Household survey of 100 households and participatory mapping in Mathare

Co-design workshop with community members; government officials and experts to co-design energy system options for Mathare (19 participants)

Policy seminar with community members; government officials and experts to discuss policy options for the energy-health nexus in Kenya (27 participants)

Dissemination workshop to launch: "Mathare energy stories" booklet, which contained highlights from the household survey and comic-strip illustrations of energy stories as told by Mathare community members (20 participants).

Collaborative activities Global and Regional agendas

\section{SDG 3: Ensure healthy lives and promote well-being for all at all ages}

SDG 5: Achieve gender equality and empower all women and girls.

SDG 7: Ensure access to affordable, reliable, sustainable and modern energy for all.

SDG 11: Make cities inclusive, safe, resilient and sustainable.

Africa Agenda 2063 (African Union 2016): The agenda calls for the strategic exploitation of all possible opportunities to ensure positive socioeconomic transformation within the next 50 years.

National agendas Kenya Vision 2030: generation of more energy at a lower cost and increased efficiency.

Knowledge partners

Mathare co-researchers: Community leaders, energy service providers, residents

Policy actors from: Ministry of Energy; Energy Regulatory Commission; Kenya Power; Nairobi County Council (Health department) Researchers and experts from: University of Nairobi Stockholm Environment Institute (SEI); Institut de recherche pour le développement (IRD-Kenya)

Co-funding

\begin{abstract}
Uganda Vision 2040: improving energy efficiency by promoting use of energy efficient technologies
\end{abstract}

Community co-researchers from LUCHACOS (a community-based group in Kasubi-Kawaala

Policy actors from Uganda National Planning Authority
Previous study based on a household survey of 100 Integrated Assessment of Societal and Ecosystem Metabolism (MuSIASEM)

Policy seminar with community members; government officials and experts to discuss policy options for the energy-gender-health nexus in South Africa (20 participants).

Dissemination workshop to launch a joint policy brief on: "Mediating household energy-healthgender nexus transition through co-design and policy integration in urban Africa" (13 participants) households in Enkanini using the Multi-Scale
National development plan; Vision for 2030: providing options for increasing access to modern, affordable and sustainable forms of energy to the urban informal poor.

Community co-researchers from Enkanini; Officials from: Stellenbosch municipality; Department of nergy in the Western Cape; Researchers from: Stellenbosch University; UNEP South Africa office
Knowledge products Co-design impact AfriCLP program for policy engagement in Kenya

Stellenbosch University funding for Postdoctoral fellow to carry out comparative data analyses for the CoDEC entire team.

Blogposts; Project documentary; Mathare energy stories; Submitted journal articles; Policy brief; Conference Presentations; postgraduates;

Improved awareness of energy-gender-health nexus; co-learning across, within, and beyond academia to influence policy and community stakeholders
'Energy is central to nearly every major challenge and opportunity the world faces today. It is the key to successful poverty reduction, social progress, equity, enhanced resilience, economic growth, and, if developed appropriately, environmental sustainability.' (DoE 2015). ${ }^{8}$

In Kenya, the main objectives of Vision 2030 are:

'...accelerating economic growth; increasing productivity of all sectors; equitable distribution of national income; poverty alleviation through improved access to basic needs; enhanced agricultural production; industrialisation; accelerated employment creation and improved ruralurban balance. The realisation of these objectives will be feasible if

\footnotetext{
${ }^{8}$ Department of Energy, 2018. Independent Power Producers Procurement Programme. South Africa Republic of South Africa.
}

quality energy services are availed in a sustainable, competitive, cost effective and affordable manner to all sectors of the economy ranging from manufacturing, services, mining, and agriculture to households' (MoEP, 2015). ${ }^{9}$

The Ugandan government equally states that:

'Access to modern and clean energy services is a necessary precondition for achieving development goals that extend far beyond the energy sector, such as poverty eradication, access to clean water, improved public health and education, women's empowerment and increased food production.' (MoEMD, 2015). ${ }^{10}$

\footnotetext{
${ }^{9}$ Ministry of Energy and Petroleum, 2015. Draft National Energy and Petroleum Policy. Government of Kenya.

${ }^{10}$ Ministry of Energy and Mineral Development, 2015. Uganda's Sustainable
} 
Table 2

Cross-cutting themes of an energy policy mix framework.

Source: Authors.

\begin{tabular}{|c|c|c|c|}
\hline Energy policy mix & $\begin{array}{l}\text { Access to alternative energy } \\
\text { services }\end{array}$ & $\begin{array}{l}\text { Entry of the urban poor into } \\
\text { energy businesses }\end{array}$ & Reduction of energy-related health impacts \\
\hline Gender & \multicolumn{2}{|c|}{$\begin{array}{l}\text { Inclusion of women in entrepreneurship opportunities that promote } \\
\text { efficient technologies. }\end{array}$} & $\begin{array}{l}\text { Indoor air pollution affects poor women who spend more time cooking in poorly } \\
\text { ventilated dwellings. Poor women also spend more time sourcing for fuel. }\end{array}$ \\
\hline Housing & \multicolumn{2}{|c|}{$\begin{array}{l}\text { Affordable housing using sustainable materials that enhance energy } \\
\text { access and efficiency. }\end{array}$} & \\
\hline Health & \multicolumn{2}{|c|}{$\begin{array}{l}\text { Promotion of the health benefits of switching to modern fuels and } \\
\text { efficient technologies. }\end{array}$} & \\
\hline
\end{tabular}

Despite the clear vision to improve energy access at the national level, household energy access, especially for urban informal settlement households is still an uphill task in all three countries as shown by the baseline studies of the CoDEC project. Cognizant of this need, CoDEC project partners ultimately aimed to influence positive policy changes, which is key to Africa's energy transition [61,62]. In line with the call for energy policy integration [63], local research teams in each country facilitated a policy seminar aimed at engaging diverse stakeholders in tackling the policy concerns at the nexus of energy and health.

In the Kenya policy seminar, there were 27 participants from Mathare settlement, as well as from academia, the private sector and policy-makers. Two researchers from the team, a Mathare community member and a participatory mapping expert, provided an overview of the case study and its achievements. This led to brainstorming sessions on energy, health and housing concerns for informal settlements in Nairobi. The sessions were conducted in groups based on the selfidentified interests of each participant. The emerging issues were then discussed in plenary. To open up space for new perspectives, participants switched groups and engaged in user-journey mapping for a persona of their choice. The aim of this exercise was to contextualize the energy-health-housing nexus challenge by visualizing the daily practices of a typical informal settlement dweller. New insights emerged from this exercise since participants were pushed to envisage their earlier concepts as real-life situations, and then propose possible solutions. The seminar concluded with a reflection exercise on content and method.

In the Uganda case, the researchers co-facilitated a session with a community-based group that was already working on alternative energy in Kasubi-Kawaala settlement. Other participants were drawn from academia and policy bringing the total number of participants to 15 . The seminar was facilitated through a series of presentations from researchers, the community group and from policy actors. The presentations opened up discussions on: energy access in urban informal settlements, the related health outcomes of energy-poverty, renewable energy options and the wider context of urban planning for Kampala.

The South Africa policy seminar consisted of 20 participants who were: policy makers representing different levels of governance (local, provincial, national and international), community members, and academics. As a warm up, the participants were asked to indicate which of the three nexus elements: energy, health, and gender, they were most concerned with. This was followed by presentations from a community member about their day-to-day experiences on the energy issues and how this relates to health and gender, followed by the researchers' presentations on the CoDEC project. This was followed with breakaway sessions of community members group and policy group, to discuss the energy-health-gender issues in detail.

What was interesting from the policy seminars was the opportunity to bring together diverse actors who despite living or working for the

(footnote continued)

Energy for All Initiative Action Agenda. Uganda: Government of Uganda. same city, did not have any prior avenues to interact. In the Nairobi policy seminar for example, a government official admitted to having never visited Mathare nor interacted with Mathare residents. In a later dissemination workshop, the same official elaborated on how his interactions in CoDEC activities had informed discussions at his office on pro-poor and gendered solutions. In the Stellenbosch policy seminar, participants discussed the benefits of bringing together Western Cape government and Stellenbosch Municipality offices that need to work more closely to solve community challenges. In the Makerere policy seminar, community members challenged government officials to provide more enabling regulatory frameworks for their local businesses, as opposed to taking punitive measures such as heavy taxation that hamper entrepreneurship.

The researchers therefore provided a 'safe' space for actors to express themselves and possibly build trust for future collaborations. In general, policy actors across the three countries expressed the challenges they face in dealing with the precarious nature of informal settlements. Concomitantly, informal settlement dwellers emphasized their frustration and inability to influence decision-making processes at the city level. Experts and academicians for their part were most concerned with why existing knowledge and expertise has failed to solve the household energy challenge in informal settlements. It is hoped that these transdisciplinary interactions can grow into actionable efforts towards energy transition in the informal settlements.

\subsection{Towards a policy mixes framework}

The research project partners later converged at the CoDEC regional workshop to reflect on the project milestones and form a meta-analysis framework for the case study findings and stakeholder engagements. In terms of policy insights from the policy seminars, the partners formulated the policy mixes framework to articulate the challenges and opportunities for nexus policy making. A policy mix was defined as the positive interactions that emerge between two or more policy options that address a nexus challenge. As explained further by BahnWalkowiak and Wilts [64] no single policy tool can solve a complex challenge that requires multi-level and multi-stakeholder engagement. Instead, they recommend "...policy mixes at different governance scales..." to address "...variety of barriers, take separate innovation stages into account, and effectively address national and global requirements." Using this approach, the CoDEC project partners articulated four considerations for the formulation of a policy mixes framework:

- Path-dependency: disparate policies such as in energy, health and housing remain sectorial and fail to address complex challenges.

- Capacity-action gaps: policy implementation is in itself a challenge in African countries.

- Policy-patching: African governments borrow heavily from best practice and fail to contextualize solutions.

- Ambivalent energy communities: communities especially those in informal settlements are motivated by the immediacy of their needs rather than by regulation since regulatory frameworks have failed to 
provide for them.

In light of these considerations, the research partners concluded that policy options need to be considered in 'bundles'. As shown in Table 2, energy provision for urban informal settlements can be bundled in terms of gender, housing and health. In this way, policy options can be considered together to: increase access to alternative energy services; stimulate entry of the urban poor into energy businesses; and reduce energy-related health impacts.

Going forward, the partners proposed that the policy mixes framework can be used to design multisectoral policy portfolios. It is important to acknowledge however that the usefulness of such a framework can only be judged in the long-term, given the gradual unfolding of policy cycles. For now, the best that can be achieved is in influencing the agenda setting phase of future policies or the evaluation phase of current policies. This is in keeping with the call for "...revision of appropriate policies for integrated resource management able to effectively promote sustainable development at the local and global level." [65].

\section{Widening the nexus scope}

During the regional workshop, the project partners engaged with diverse stakeholders from Kenya, many of whom the Kenyan research team had worked with before. The one-day engagement was aimed at delving further into nexus issues using the Kenya case. The 39 workshop participants were drawn from the three research teams, from Mathare, as well as from policy and private sectors. Participants engaged in 'round floor' discussions focusing on five nexus themes of: innovation, research, funding, community, and science advocacy. The idea was to promote deep interactions as participants from diverse backgrounds needed to form a sense of familiarity within a short period of time. Participants also visited a community centre in Mathare, where five community members led discussions on the energy, health and housing challenges of the settlement. A synthesis of the discussions is presented in Table 3. Participant's reflections about the workshop showed that the engagement exercise was valuable in terms of diversity, generated insights, and networking opportunities. In light of this feedback, the research partners are keen to facilitate deeper interactions beyond the two-year CoDEC project.

\subsection{The role of the private sector in stimulating the nexus}

In as much as the CoDEC project partners aimed to engage diverse stakeholders in tackling the nexus challenge, the most fruitful engagements were with the informal settlement communities from the case studies and with policy actors. Engagements with the private sector were limited in scope due to time constraints and lack of prior experience in dealing with such stakeholders. Nevertheless, the role of the private sector was duly acknowledged in the regional workshop in the discussions on nexus innovations. In this regard, private sector stakeholders were recognized for their keen understanding of the market, and their role in innovating and availing energy goods and services in a sustainable manner.

As discussed in the regional workshop, innovations to the nexus challenge need to be socio-technological, meaning that consideration is given to cross-cutting issues that improve access and uptake, promote health, and provide economic empowerment. In their role as innovators, private sector stakeholders should thus ensure that the technologies they provide have co-benefits and enhance knowledge transfer.

Going forward, the CoDEC project partners hope to engage more closely with private sector associations in the energy sector such as the Kenya Renewable Energy Association, South African Renewable Energy Council, and Uganda National Renewable Energy and Energy Efficiency Alliance. These associations represent private sector companies that

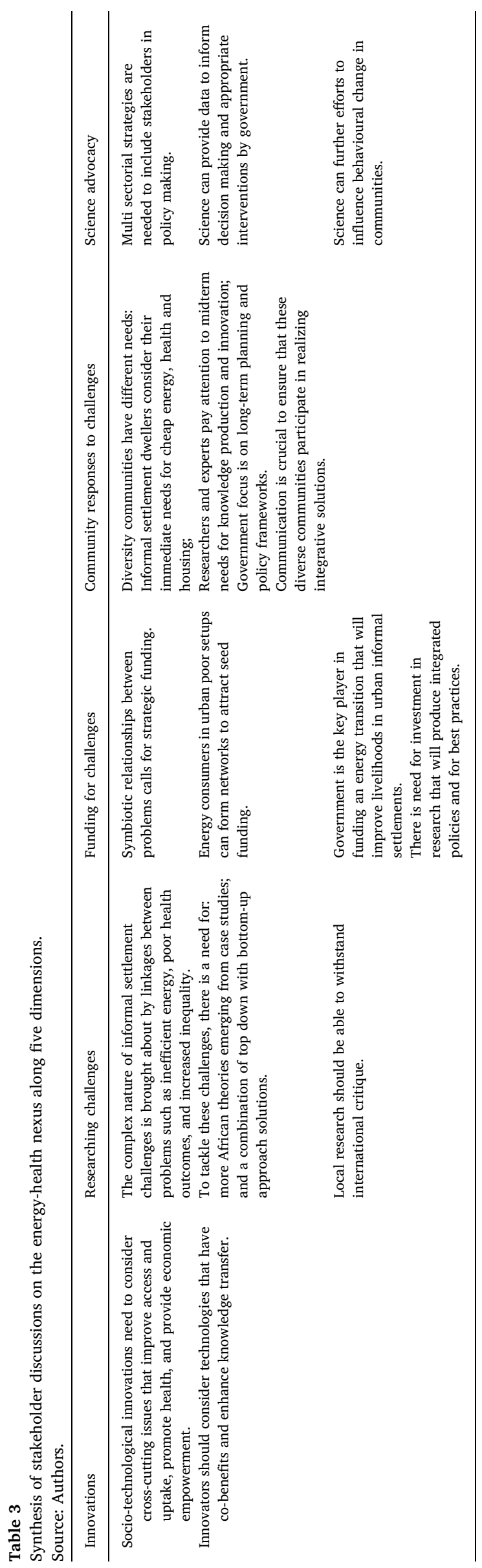


provide renewable energy goods and services in the three countries that were studied. As such, these associations have the convening power and experience required to initiate and sustain changes in the energy market through innovation. The members of these private sector associations can therefore 'stimulate the nexus' by providing sustainable energy solutions.

Ultimately, there is need for further experimentation to build energy communities that can take advantage of Africa's vast renewable energy potential and the investments this is going to attract. According to the International Renewable Energy Agency, Eastern and Southern Africa are especially well positioned geographically for renewable energy development along the "Africa Clean Energy Corridor". ${ }^{11}$ If so, then Kenya, Uganda and South Africa, among other countries in this subregion should gear up to transform their energy sectors. For households in these countries, the opportunity is rife for exploring innovative models for energy communities that use distributed renewable energy options.

In informal settlements such as Mathare, Enkanini and KasubiKawaala, place-based energy communities can be instituted through long-term research engagements by local researchers, who in turn can pull in trans-local knowledge and resources, while broadening the scientific knowledge base on energy transitions. Given that Africa's energy future remains uncertain [66], and therefore open, there is ample opportunity to explore innovative alternatives that bypass the technological lock-ins that characterize the fossil-based systems of industrial economies.

\section{Conclusion}

The dynamic participation of stakeholders in the CoDEC project activities demonstrate that stakeholders are generally interested in multi-sectorial engagement. However, there seems to be no sustained effort, especially on the part of governments, to implement frameworks or platforms that would enhance collaboration and policy integration to improve sustainable energy access in urban informal settlements. Local researchers therefore are tasked with producing relevant knowledge that is cognizant of community realities and is relevant for policy action. Producing such knowledge calls for longer-term research collaborations that are well-resourced. In this regard, the CoDEC project has barely scratched the surface of a complex challenge. Nevertheless, the partners have demonstrated how "...essential relationships and ongoing practices..." can be altered to build networks of change agents [67].

As CoDEC project partners, we set out to integrate existing solutions by bringing together diverse stakeholders who would ordinarily not work together. This was exemplified in the policy seminars, where government officials from national and local levels, interacted with researchers, community members and private sector individuals. Private sector stakeholders were however not adequately represented in the project engagements due to the convenience sampling approach of the study, which meant that research teams were mostly relying their limited existing relationships. In future, the partners hope to mitigate this shortcoming by consulting and working more closely with renewable energy associations, which are well established in the three countries. In this way, the researchers will enhance their role as knowledge intermediaries.

In terms of reach, the CoDEC project attracted considerable international interest in significant research forums in 2018 in which different researchers from the CoDEC team were invited to present on the project. Some of the notable presentations were at: the United Nations science technology and innovation forum in New York; the Seedbeds of transformation in Port Elizabeth, South Africa; the Gordon research conference - industrial ecology in Switzerland. During these events, the participating CoDEC research team members sought to forge new partnerships with the aim of harnessing more resources for the continuation of the project. An example of such an interaction is ongoing between the CoDEC team in Kenya and the Renewable Energy, Nutrition, Environment, Water, and Waste (RENEWW) Innovation Zones team based in the United States ${ }^{12}$. The RENEWW Zones model of providing decentralized, closed-loop services in peri-urban areas offers a promising holistic approach that can leverage the in-depth contextual experience of the CoDEC research partners.

More importantly, the impact of CoDEC is in working with informal settlement community members, who, due to their lived experience, are in effect the knowledge experts on how to tackle the household energy challenge in urban Africa. By working with community members as coresearchers and carrying out field studies using multiple methods, the CoDEC research partners used their resources and expertise to trigger synergies between the informal, tacit knowledge of community members, and the more formal processes of policy making and private sector innovation. More work needs to be done in ensuring that these synergies lead to concrete sustainable solutions.

Another significant outcome of the project is the participation of graduate students from the respective host universities as field research assistants in the case studies. In Kenya, one graduate student successfully defended her thesis that was based entirely on the field work in Mathare. By working with students, the researchers fulfilled one of their research objectives of building local capacity for doing transdisciplinary research.

From the CoDEC project experience, it is clear that transdisciplinary co-design approaches are useful in unearthing the extent of a complex challenge through long-term engagement. Local researchers are well placed to engage in long-term transdisciplinary research processes that facilitate and support urban network compositions. Such networks of urban intermediaries drawn from academia, public and private sectors, as well as from local communities and civil society, need facilitation to work in shared spaces where they can co-design socio-technical innovations. For researchers, the co-generation of quality scientific knowledge is an added motivation to engage in transdisciplinary codesign research. In carrying out such research and engagements, it is necessary to acknowledge and deal with conflicts such as local competing interests and foreign agendas that may not be aligned with the social good that transdisciplinary research aims for. Researchers have to therefore be reflective of their own practice and of their engagements.

The CoDEC project has also demonstrated that household energy transitions should be tackled with a multi-perspective lens that looks at historical, socio-spatial political and cultural issues that interact to form energy geographies. The research partners unearthed the socio-spatial aspects of energy access in three urban informal settlements using household surveys and participatory mapping tools. These findings became engagement tools or boundary objects to interact with stakeholders to better understand the wider social constructivist dimensions of energy as shaped by local contexts. By approaching energy as a nexus problem, the partners further sought to visualize the interactions between urban system services. In so doing, the partners gained a considerable understanding of the network of actors who can collaborate to achieve sustainable energy communities in the three cities of study. Going forward, the aim is to sustain the emergent networks in order to achieve greater impact for communities.

As advised by Sovacool et al. [68] this paper set out to articulate the rigor that is required in energy social research. We hope we have shown the rigor of our work by explicating its inter- and trans- disciplinary nature, as well as the policy-relevance of our approach. By sharing knowledge products in different formats through research forums and online platforms, we have further shown the diversity of energy social research. This sharing of knowledge was beneficial for us in that it

\footnotetext{
${ }^{11}$ https://www.irena.org/cleanenergycorridors/Africa-Clean-EnergyCorridor.
}

${ }^{12}$ https://penniur.upenn.edu/initiatives/reneww. 
allowed us to modify our approach in answer to emerging realities.

Sharing lessons also offered the opportunity for others to learn from our successes and improve on our shortcomings, thereby enhancing generalizability of our work. Admittedly, our context-specific results such as the household data may not be relevant for dissimilar cases. However, we believe that the co-design stance and stakeholder engagement approach that we have elaborated in this paper is widely generalizable to energy-related contexts, in which researchers have to work as knowledge intermediaries. Ultimately, we aim to influence energy policy and markets in African countries to become more inclusive. We believe this will result in solutions that interactively address the complex challenge of providing sustainable clean energy for Africa's fast-growing urban population.

\section{Acknowledgments}

The CoDEC research project is supported by Leading Integrated Research for Agenda 2030 in Africa (LIRA2030) program. LIRA2030 is a five-year program aimed at supporting collaborative research projects led by early-career researchers across Africa. The program is being implemented by the International Science Council (ISC), in partnership with the Network of African Science Academies (NASAC), with support from the Swedish International Development Cooperation Agency (Sida). Additional funding for policy work in Nairobi came from the Africa Climate Change Leadership (AfriCLP) program. AfriCLP is managed by University of Nairobi and is funded by the International Development Research Centre (IDRC). The corresponding author refined this paper while on a research fellowship at the Leicester Institute of Advanced Studies, University of Leicester, UK. Stellenbosch University Research Office and Stellenbosch University International supported the project with a 2-year Post-doctoral Fellowship and project team mobility exchanges respectively.

\section{References}

[1] M. Bazilian, P. Nussbaumer, G. Gualberti, E. Haites, M. Levi, J. Siegel, et al., Informing the financing of universal energy access: an assessment of current financial flows, Electr. J. 24 (7) (2011) 57-82.

[2] J.E. Aldy, W.A. Pizer, The competitiveness impacts of climate change mitigation policies, J. Assoc. Environ. Resour. Econ. 2 (4) (2015) 565-595.

[3] SEforALL, Sustainable Energy for All, Retrieved 20th December, 2018, from (2019) https://www.seforall.org/about-us.

[4] UN-HABITAT, The State of African Cities 2014: Re-Imagining Sustainable Urban Transitions: United Nations Human Settlements Programme, (2015).

[5] M.G. Pollitt, The role of policy in energy transitions: lessons from the energy liberalisation era, Energy Policy 50 (2012) 128-137.

[6] P. Newell, J. Phillips, Neoliberal energy transitions in the South: Kenyan experiences, Geoforum 74 (2016) 39-48.

[7] B.K. Sovacool, F.W. Geels, Further reflections on the temporality of energy transi tions: a response to critics, Energy Res. Soc. Sci. 22 (2016) 232-237.

[8] U.E. Hansen, I. Nygaard, H. Romijn, A. Wieczorek, L.M. Kamp, L. Klerkx, Sustainability Transitions in Developing Countries: Stocktaking, New Contributions and a Research Agenda, Elsevier, 2018.

[9] K.J. Hancock, The expanding horizon of renewable energy in sub-Saharan Africa: leading research in the social sciences, Energy Res. Soc. Sci. 5 (2015) 1-8.

[10] B.K. Sovacool, The political economy of energy poverty: a review of key challenges, Energy Sustain. Dev. 16 (3) (2012) 272-282.

[11] L. Baker, P. Newell, J. Phillips, The political economy of energy transitions: the case of South Africa, New Political Econ. 19 (6) (2014) 791-818.

[12] M. Davies, M. Swilling, H.L. Wlokas, Towards new configurations of urban energy governance in South Africa's Renewable Energy Procurement Programme, Energy Res. Soc. Sci. 36 (2018) 61-69.

[13] L. Agbemabiese, J. Nkomo, Y. Sokona, Enabling innovations in energy access: an African perspective, Energy Policy 47 (2012) 38-47.

[14] C.L. Azimoh, P. Klintenberg, F. Wallin, B. Karlsson, Illuminated but not electrified: an assessment of the impact of Solar Home System on rural households in South Africa, Appl. Energy 155 (2015) 354-364.

[15] J.M. Eder, C.F. Mutsaerts, P. Sriwannawit, Mini-grids and renewable energy in rural Africa: how diffusion theory explains adoption of electricity in Uganda, Energy Res. Soc. Sci. 5 (2015) 45-54.

[16] M.B. Pedersen, Deconstructing the concept of renewable energy-based mini-grids for rural electrification in East Africa, Wiley Interdiscip. Rev. Energy Environ. 5 (5) (2016) 570587.

[17] K. Kaygusuz, Energy for sustainable development: a case of developing countries, Renewable Sustainable Energy Rev. 16 (2) (2012) 1116-1126.
[18] N. Bruce, D. Pope, E. Rehfuess, K. Balakrishnan, H. Adair-Rohani, C. Dora, WHO indoor air quality guidelines on household fuel combustion: strategy implications of new evidence on interventions and exposure-risk functions, Atmos. Environ. 106 (2015) 451-457.

[19] N.L. Lam, K.R. Smith, A. Gauthier, M.N. Bates, Kerosene: a review of household uses and their hazards in low-and middle-income countries, J. Toxicol. Environ. Health Part B 15 (6) (2012) 396-432.

[20] Z. Kovacic, S. Smit, J.K. Musango, A.C. Brent, M. Giampietro, Probing uncertainty levels of electrification in informal urban settlements: a case from South Africa, Habitat Int. 56 (2016) 212-221.

[21] F.M. Butera, P. Caputo, R.S. Adhikari, A. Facchini, Urban development and energy access in informal settlements. A review for Latin America and Africa, Procedia Eng 161 (2016) 20932099.

[22] M. González-Eguino, Energy poverty: an overview, Renewable Sustainable Energy Rev. 47 (2015) 377-385.

[23] G. Hutton, E. Rehfuess, F. Tediosi, S. Weiss, W.H. Organization, Evaluation of the Costs and Benefits of Household Energy and Health Interventions at Global and Regional Levels, (2006)

[24] M. Njenga, N. Karanja, H. Karlsson, R. Jamnadass, M. Iiyama, J. Kithinji, C. Sundberg, Additional cooking fuel supply and reduced global warming potential from recycling charcoal dust into charcoal briquette in Kenya, J. Clean. Prod. 81 (2014) 81-88.

[25] C. Ochieng, S. Vardoulakis, C. Tonne, Household air pollution following replacement of traditional open fire with an improved rocket type cookstove, Sci. Total Environ. 580 (2017) 440-447.

[26] C.T. Ghergu, A. Meershoek, P. Sushama, O.C. van Schayck, L.P. de Witte, Participation in co-design: in search of a recipe for improved cookstoves in urban Indian slums, Action Res. (2018) 1476750317754125.

[27] T. Sesan, Navigating the limitations of energy poverty: lessons from the promotion of improved cooking technologies in Kenya, Energy Policy 47 (2012) 202-210.

[28] J. Rosenthal, A. Quinn, A.P. Grieshop, A. Pillarisetti, R.I. Glass, Clean cooking and the SDGs: integrated analytical approaches to guide energy interventions for health and environment goals, Energy Sustain. Dev. 42 (2018) 152-159.

[29] A.V. Shankar, M. Onyura, J. Alderman, Agency-based empowerment training en hances sales capacity of female energy entrepreneurs in Kenya, J. Health Commun. 20 (sup1) (2015) 67-75.

[30] O.W. Johnson, V. Gerber, C. Muhoza, Gender, culture and energy transitions in rural Africa, Energy Res. Soc. Sci. 49 (2019) 169-179.

[31] T. Egondi, C. Kyobutungi, N. Ng, K. Muindi, S. Oti, Svd Vijver, et al., Community perceptions of air pollution and related health risks in Nairobi slums, Int. J. Environ. Res. Public Health 10 (10) (2013) 4851-4868.

[32] K. Muindi, T. Egondi, E. Kimani-Murage, J. Rocklov, N. Ng, "We are used to this": a qualitative assessment of the perceptions of and attitudes towards air pollution amongst slum residents in Nairobi, BMC Public Health 14 (1) (2014) 226.

[33] I. Baptista, Space and energy transitions in sub-Saharan Africa: understated historical connections, Energy Res. Soc. Sci. 36 (2018) 30-35.

[34] S. Bouzarovski, S. Petrova, A global perspective on domestic energy deprivation: overcoming the energy poverty-fuel poverty binary, Energy Res. Soc. Sci. 10 (2015) $31-40$.

[35] F. Boamah, E. Rothfuß, From technical innovations towards social practices and socio-technical transition? Re-thinking the transition to decentralised solar PV electrification in Africa, Energy Res. Soc. Sci. 42 (2018) 1-10.

[36] J. Mattes, A. Huber, J. Koehrsen, Energy transitions in small-scale regions-What we can learn from a regional innovation systems perspective, Energy Policy 78 (2015) 255-264.

[37] B. Batinge, J.K. Musango, A.C. Brent, Leapfrogging to renewable energy: the opportunity for unmet electricity markets, South Afr. J. Ind. Eng. 28 (4) (2017) 32-49.

[38] S.J. Klein, S. Coffey, Building a sustainable energy future, one community at a time, Renewable Sustainable Energy Rev. 60 (2016) 867-880.

[39] DECC - Department of Energy, and Climate Change, Community Energy Strategy. Full Report, Department of Energy and Climate Change, London, 2014.

[40] G. Seyfang, A. Haxeltine, Growing Grassroots Innovations: Exploring the Role of Community Based Initiatives in Governing Sustainable Energy Transitions, SAGE Publications Sage UK, London, England, 2012.

[41] T. Van Der Schoor, B. Scholtens, Power to the people: local community initiatives and the transition to sustainable energy, Renewable Sustainable Energy Rev. 43 (2015) 666-675.

[42] S. Becker, C. Kunze, M. Vancea, Community energy and social entrepreneurship: addressing purpose, organisation and embeddedness of renewable energy projects, J. Clean. Prod. 147 (2017) 25-36.

[43] S.M. Hoffman, A. High-Pippert, From private lives to collective action: recruitment and participation incentives for a community energy program, Energy Policy 38 (12) (2010) 7567-7574.

[44] J. Hamilton, R. Mayne, Y. Parag, N. Bergman, Scaling up local carbon action: the role of partnerships, networks and policy, Carbon Manag. 5 (4) (2014) 463-476.

[45] E. Heaslip, F. Fahy, Developing transdisciplinary approaches to community energy transitions: an island case study, Energy Res. Soc. Sci. 45 (2018) 153-163.

[46] F. Ceschin, How the design of socio-technical experiments can enable radical changes for sustainability, Int. J. Design 8 (3) (2014) 1-21.

[47] C. Vezzoli, E. Delfino, L.A. Ambole, System Design for Sustainable Energy for all. A new challenging role for design to foster sustainable development, Form Akademisk-Res. J. Design Design Educ. 7 (3) (2014).

[48] L.A. Ambole, M. Swilling, M.K. M'Rithaa, Designing for Informal Contexts: A Case Study of Enkanini Sanitation Intervention, (2016).

[49] R. Shelby, Y. Perez, A. Agogino, Partnering with the Pinoleville Pomo Nation: codesign methodology case study for creating sustainable, culturally inspired 
renewable energy systems and infrastructure, Sustainability 4 (5) (2012) 794-818.

[50] F. Ssozi-Mugarura, E. Blake, U. Rivett, Codesigning with communities to support rural water management in Uganda, CoDesign 13 (2) (2017) 110-126.

[51] C.F. Yang, T.J. Sung, Service design for social innovation through participatory action research, Int. J. Design 10 (1) (2016) 21-36.

[52] T. Brown, B. Katz, Change by design, J. Prod. Innov. Manage. 28 (3) (2011) 381-383.

[53] E. Manzini, Making things happen: social innovation and design, Des. Issues 30 (1) (2014) 57-66.

[54] I. Etikan, S.A. Musa, R.S. Alkassim, Comparison of convenience sampling and purposive sampling, Am. J. Theor. Appl. Stat. 5 (1) (2016) 1-4.

[55] C.O.R.C. Stellenbosch Municipality, Enkanini (Kayamandi) Household Enumeration Report Stellenbosch, South Africa, (2012).

[56] S. Smit, J.K. Musango, Z. Kovacic, A.C. Brent, Towards measuring the informal city: a societal metabolism approach, J. Ind. Ecol. (2018).

[57] J. Van Breda, M. Swilling, The guiding logics and principles for designing emergent transdisciplinary research processes: learning experiences and reflections from a transdisciplinary urban case study in Enkanini informal settlement, South Africa, Sustain. Sci. (2018) 1-19.

[58] M. Polk, J.-H. Kain, Co-Producing Knowledge for Sustainable Urban Futures CoProducing Knowledge for Sustainable Cities, Routledge, 2015, pp. 17-38.

[59] A.I. Gaziulusoy, C. Boyle, Proposing a heuristic reflective tool for reviewing literature in transdisciplinary research for sustainability, J. Clean. Prod. 48 (2013) 139-147.
[60] N. Schäpke, F. Stelzer, G. Caniglia, M. Bergmann, M. Wanner, M. Singer-Brodowski, et al., Jointly experimenting for transformation? Shaping real-world laboratories by comparing them, GAIA-Ecol. Persp. Sci. Soc. 27 (1) (2018) 85-96.

[61] M.S.B. Aïssa, M.B. Jebli, S.B. Youssef, Output, renewable energy consumption and trade in Africa, Energy Policy 66 (2014) 11-18.

[62] N.S. Ouedraogo, Africa energy future: alternative scenarios and their implications for sustainable development strategies, Energy Policy 106 (2017) 457-471.

[63] D. Van Vuuren, N. Nakicenovic, K. Riahi, A. Brew-Hammond, D. Kammen, V. Modi, et al., An energy vision: the transformation towards sustainability-interconnected challenges and solutions, Curr. Opin. Environ. Sustain. 4 (1) (2012) 18-34.

[64] B. Bahn-Walkowiak, H. Wilts, The institutional dimension of resource efficiency in a multilevel governance system-implications for policy mix design, Energy Res. Soc. Sci. 33 (2017) 163-172.

[65] S. Mandelli, J. Barbieri, L. Mattarolo, E. Colombo, Sustainable energy in Africa: a comprehensive data and policies review, Renewable Sustainable Energy Rev. 37 (2014) 656686.

[66] P.L. Lucas, J. Nielsen, K. Calvin, D.L. McCollum, G. Marangoni, J. Strefler, et al., Future energy system challenges for Africa: insights from Integrated Assessment Models, Energy Policy 86 (2015) 705-717.

[67] D. Mitlin, S. Bartlett, Editorial: co-production - key ideas, Environ. Urban. 30 (2) (2018) 355-366, https://doi.org/10.1177/0956247818791931.

[68] B.K. Sovacool, J. Axsen, S. Sorrell, Promoting novelty, rigor, and style in energy social science: towards codes of practice for appropriate methods and research design, Energy Res. Soc. Sci. (2018). 